\title{
Room Temperature Tensile Properties of Fe-Al Single Crystals $80902-$ Strengthened by Excess Vacancies
}

\author{
K. Yoshimi ${ }^{2}{ }^{1}$, Y. Saeki ${ }^{\text {b. }}{ }^{2}$, M. H. Yoo ${ }^{c}$ and S. Hanada ${ }^{a}$ \\ ${ }^{2}$ Institute for Materials Research, Tohoku University, Sendai 980-77, Japan \\ ${ }^{\mathrm{b}}$ Graduate Student, Department of Materials Processing, Tohoku University, Sendai 980-77, Japan \\ ${ }^{`}$ Metals and Ceramics Division, Oak Ridge National Laboratory, Oak Ridge, TN 37831-6115, USA

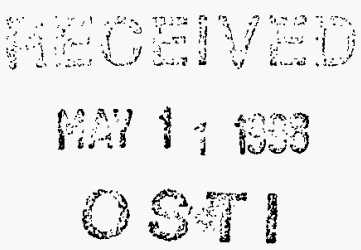

Abstract

Effects of supersaturated excess vacancies on plastic deformation of $\mathrm{Fe}-\mathrm{Al}$ were investigated by tensile testing at room temperature three different single crystals (Fe-33, 41 and $44 \mathrm{~mol} . \% \mathrm{Al})$. Critical resolved shear stresses (CRSSs) of slowly-cooled specimens (as-homogenized specimens) and wellannealed specimens (vacincy-eliminated specimens) were almost the same and did not show Al concentration dependence. On the other hand, the CRSS of vacancy-containing specimens (fast-cooled specimens) wals significantly higher than that of the others, even for Fe-33mol. \% Al, and showed strong Al concentration dependence. The fast-cooled specimens displayed serrated flow behavior during workhardening at room temperature, and the serrated flow was more intensive at a higher Al composition. Deformation microstructures of Fe-44mol. \%Al were examined by TEM, and it was found that dislocations in fast-cooled specimen were inhomogeneously distributed, suggesting jerky motion of slip dislocations. These dislocations were oriented along an unstable direction estimated from dislocation line tension. In addition. there were numerous dislocation loops. A dislocation mechanism of the

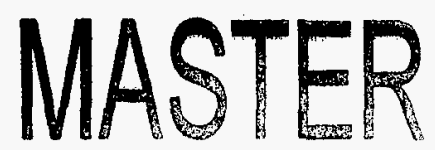

' Present address: Metals and Ceramics Division. Oak Ridge National Laboratory, Oak Ridge. TN 37831-6115. USA

: Present address: Printed Wiring Board Div.. Process Technology Development Dept.. Fujitsu Co.. Ltd. 36 Kitamaribe. Nagano 381 . Japan 


\section{DISCLAIMER}

This report was prepared as an account of work sponsored by an agency of the United States Government. Neither the United States Government nor any agency thereof, nor any of their employees, make any warranty, express or implied, or assumes any legal liability or responsibility for the accuracy, completeness, or usefulness of any information, apparatus, product, or process disclosed, or represents that its use would not infringe privately owned rights. Reference herein to any specific commercial product, process, or service by trade name, trademark, manufacturer, or otherwise does not necessarily constitute or imply its endorsement, recommendation, or favoring by the United States Government or any agency thereof. The views and opinions of authors expressed herein do not necessarily state or reflect those of the United States Government or any agency thereof. 
excess vacancy strengthening is discussed on the basis of the experimental results.

\section{Introduction}

It is well-known that excess vacancy strengthening is significant at low temperatures in $\mathrm{Fe}-\mathrm{Al}$. particularly in B2-FeAl. Special attention has been paid to this phenomenon since Nagpal and Baker reported the composition and cooling rate dependence of hardness in B2-FeAl [1]. This phenomenon was first reported by Rieu and Goux [2]. They revealed that B2-FeAl quenched rapidly from elevated temperatures retains a high concentration of thermal vacancies, and that the retained excess vacancies enhance hardness [2]. Since the excess vacancy concentration increases with increasing Al concentration, the strength of the iron aluminides exhibits strong composition dependence, if samples are subjected to the same thermal histories $[1,3-5]$. Furthermore it has been found that there is a linear relationship between the hardness and the square root of vacancy concentration [4].

One of the remaining problems is how Fe-Al is strengthened by excess vacancies. Kimura and Maddin [6] reviewed vacancy strengthening in fec metals and considered that the strengthening is caused by interaction of dislocitions with "observable vacancy clusters" and by super-jog formation due to condensation of vacancies on dislocations. In the case of B2-FeAl, however, the excess vacincy strengthening is likely to occur by mechanism(s) different from that in fec metals, because (i) FeAl does not exhibit age-hardening but rather softens $[2,3,7]$, unlike fec metals that are hardened primarily by aging rather than by quenching. and (ii) vacancy cluster defects such as prismatic dislocation loops and stacking fault tetrahedra are not usually observed in as-quenched FeAl. so called the observable vacancy clusters. There are a couple of exceptions to the latter, however. Crimp and Vedula [8] investigated the compressive properties of FeAl single crystals strengthened by excess vacincies at room temperature. and found that many dislocation loops are formed by deformation. Morris et al. [9] observed void formation, likely by vacancy agglomeration. Although the formation of these defects can be attributed to excess vacancies, the strengthening mechanism has not been understood yet. 
In order to understand the strengthening mechanism(s), it is required to investigate plastic deformation of vacancy-strengthened Fe-Al in more detail. The purpose of this study is to obtain tensile properties of single crystals strengthened by excess vacancies. After deformation, post-mortem deformation microstructures are observed in a transmission electron microscope (TEM), and the strengthening mechanism is discussed.

\section{Experimental details}

The master $\mathrm{Fe}-\mathrm{Al}$ alloy ingots were made by arc-melting in an argon atmosphere from $99.99 \%$ pure aluminum and iron. Single crystal rods of about $25 \mathrm{~mm}$ in diameter were grown from the master ingots by the Bridgman technique. Chemical analysis gave three single crystals of compositions, Fe-33, 41 and $44 \mathrm{~mol}$. \% Al, respectively. Hereafter, the compositions are described as Fe-33Al, Fe-41 Al and $\mathrm{Fe}-44 \mathrm{Al}$ throughout this paper. These crystals were homogenized at $1373 \mathrm{~K}$ for $48 \mathrm{~h}$ in vacuum. and then slowly cooled to room temperature at the rate of $5 \times 10^{-3} \mathrm{~K} \cdot \mathrm{s}^{-1}$. Oriented tensile specimens were cut from the homogenized crystals by an electro-discharging machine (EDM). The specimen shape and size are described in Fig. 1(a), and the tensile axis is shown in Fig. 1(b). A few specimens of the three single crystals were vacuum-scaled in silica tubes, and re-annealed at $1173 \mathrm{~K}$ for $1 \mathrm{~h}$. and then fast cooled by laking the silical tubes out of the furnace. A few specimens of the three single crystals were further annealed at $698 \mathrm{~K}$ for $100 \mathrm{~h}$ in vacuum to eliminate supersaturated excess vacancies, and then furnace-cooled without controlling the cooling ratc. As-homogenized tensile specimens are designated as "Specimen A", fast cooled ones as "Specimen B", and fully annealed ones at $698 \mathrm{~K}$ as "Specimen C". The thermal histories mentioned above are shown schematically in Fig. 2. Before tensile tests. specimen surfices were mechanically polished and electropolished in a $10 \%$ perchloric acid-methanol solution at voltage of $10.5 \mathrm{~V}$ and temperature of about $248 \mathrm{~K}$.

Tensile tests were conducted using an Instron 8562-type machine in a vacuum better than $2 \times 10$.

\footnotetext{
'Pal at room temperature. All load-displacement data were recorded in two ways with analogue and
} 
digital signals. The displacement was measured with an extensometer equipped outside the furnace. An initial strain rate in the range of $1.6 \times 10^{-2}$ to $1.6 \times 10^{-6} \mathrm{~s}^{-1}$ was applied. Some specimens were strained to about $4 \%$ at $1.6 \times 10^{-4} \mathrm{~s}^{-1}$, and disks parallel to the ( $\overline{1} 01$ ) plane were sectioned from them by EDM. Thin foils for TEM observation were produced by electropolishing these disks in a Struers Tenupol-3 in a $33 \%$ nitric acid-methanol solution at $4 \mathrm{~V}$ and $248 \mathrm{~K}$. TEM observation was performed in a Hitachi H-8100D electron microscope at $200 \mathrm{kV}$.

\section{Results}

Figure 3 shows resolved shear stress - strain curves of the three specimens deformed at 1.6 $\times 10^{-4} \mathrm{~s}^{-1}$. All of the specimens were deformed to failure. The resolved shear stresses and the shear strains are calculated assuming the (101)[111] primary slip system, which is the most reasonable one according to earlier work $[8,10,11]$. All the the as-homogenized and vacancy-eliminated specimens (Specimens A and C) start to work harden immediately after yielding (i.e., no yield-drop). This workhardening rates gradually accelerate with strain, and merge into a linear stage (stage II). The plastic flow behavior of fast-cooled specimens (Specimens B) is distinctly different from that of Specimens A and C. The CRSSs are increased by fast cooling even in Fe-33Al. However, elongation is reduced significiantly, at higher $\mathrm{Al}$ concentrations. It should be noted that Specimens B display serrated flow after a discontinuous yiclding followed by distinct work-hardening. In Fe-4I and 44Al, this serrated How behavior continues until the specimens failed. and is more pronounced at the higher Al concentration. as shown in Fig. 4. It is believed that all these differences in Specimens B are attributed to excess vacancies retained by fast-cooling.

Figure 5 shows the variation of CRSS at the strain rate of $1.6 \times 10^{-4} \mathrm{~s}^{-1}$ with Al concentration. While the CRSSs of Specimens C are slightly lower than those of Specimens A, they are essentially independent of Al concentration. On the other hand. the CRSS of Specimens B shows a strong dependence on Al concentration. The difference between CRSS of Specimen B and others is significant 
$(\sim 50 \%)$ at $33 \mathrm{~mol}$.\%Al. Moreover, the CRSS is nearly four times higher than that of Specimens A and $\mathrm{C}$ at $44 \mathrm{~mol}$ \% Al. These results are in agreement with the Vickers hardnesses reported in previous papers $[1,3-5]$.

Figure 6 shows the variation of work-hardening rate in stage II against $\mathrm{Al}$ concentration, at a strain rate of $1.6 \times 10^{-4} \mathrm{~s}^{-1}$. At $33 \mathrm{~mol} . \% \mathrm{Al}$, the work-hardening rate is almost the same in the three Specimens. In the $\mathrm{B} 2$ region, the work-hardening rates of Specimens $\mathrm{A}$ and $\mathrm{C}$ are also almost the same but higher than Fe-33Al. On the other hand, the work-hardening rate of Specimens B is distinctly lower than the others. In particular, the value of $\mathrm{Fe}-44 \mathrm{Al}$ is smaller than that of $\mathrm{Fe}-41 \mathrm{Al}$. The decrease in work-hardening rate due to excess vacancies was also reported in the earlier studies that were carried out using single crystals under compression [12, 13].

Effects of strain rate on tensile flow properties were also examined. Figure 7 shows resolved shear stress-strain curves of Specimens $\mathrm{A}$ and $\mathrm{C}$ of Fe-4lAl obtained by strain-rate change tests. The initial nominal strain rate is $1.6 \times 10^{-4} \mathrm{~s}^{-1}$. The upward arrows correspond to a ten-fold increase of the cross-head speed (i.e. $\dot{\varepsilon}=1.6 \times 10^{-4} \mathrm{~s}^{-1} \rightarrow 1.6 \times 10^{-5} \mathrm{~s}^{-1}$ ), and the downward arrows correspond to a ten-fold decrease (i.e. $\dot{\varepsilon}=1.6 \times 10^{-5} \mathrm{~s}^{-1} \rightarrow 1.6 \times 10^{-4} \mathrm{~s}^{-1}$ ). The dotted curve is the resolved shear stress-strain plot of Specimen C obtained in a normal tensile test without a strain-rate change. When the strain-rate is decreased at the shear strain of 0.05 , the flow stress is slightly decreased initially, but it immediately begins to restore itself to give a steady work-hardening. However, by comparing the curve obtained by the strain-ratte change test with the dotted curve of Specimen C, it is seen that the incremental rate of increase in flow stress is raised only by the ten-fold decrease of strain-rate. When the strain-rate is increased, the flow stresses show a transient increase, followed by the same work-hardening rate as of the specimen under the constant strain rate (i.e., $\dot{\varepsilon}=1.6 \times 10^{-4} \mathrm{~s}^{-1}$ for the dotted curve). These flow stress changes are observed repeatedly every time the strain-rate is altered. As a result, the flow stress of Specimen $C$ gradually becomes higher as the strain increases. The same trends are seen also in Specimen $A$. This increase in flow stress by the decrease in strain-rate means a negative strain rate dependence of work-hardening rate. 
Figure 8 shows highly magnified resolved shear stress-strain curves of Specimens B of Fe41(Fig. 8(a)) and 44Al (Fig. 8(b)) obtained by strain-rate change tests. The upward and downward arrows have the same meanings as those in Fig. 7. In Specimens B, the transients in flow stress changes are not evident. Furthermore, no apparent change of serrated flow behavior is detected by strain-rate changes. As in Specimens A and C, a negative strain-rate dependence of work-hardening is found in Specimens B.

Figures 9 and 10 show deformation microstructures of Specimens $\mathrm{A}$ and $\mathrm{B}$ of $\mathrm{Fe}-44 \mathrm{Al}$ strained to about $4 \%$. The Burgers vectors of dislocations in both the microstructures were identified as $\mathbf{b}=$ [111]. The deformation microstructure shown in Fig. 10 is clearly different from that in Fig. 9, where the latter shows no specific predominant dislocation orientations similar to those of slowly-cooled B2 FeAl reported in earlier studies $[8,11,14]$. In Fig. 10, dislocations are inhomogeneously distributed in bundles, and the dislocation bundles are preferentially oriented along a direction about $56^{\circ}$ from the [111] direction. In addition, there are numerous nano-size dislocation loops having the Burgers vector parallel to the [111] direction. This inhomogeneous dislocation distribution suggests jerky motion of those dislocations during deformation, which is consistent with the appearance of serrated flow.

\section{Discussion}

\section{1. Yicld Stress}

Using positron lifetime spectroscopy, Würschum et al. [15] determined the effective enthalpy for valcancy formation to be $H_{\mathrm{v}}{ }^{\prime}=1.04 \mathrm{eV}$ and $0.98 \mathrm{eV}$ for $\mathrm{Fe}-37 \mathrm{Al}$ and $\mathrm{Fe}-39 \mathrm{Al}$, respectively, and estimated the effective enthalpy for vacancy migration to be $H_{v}{ }^{\prime \prime}=1.7 \mathrm{eV}$ for both compositions. The anomalous increase in yicld stress of B2-FeAl with increasing temperature is attributed directly to thermal vacincies [16], and a complex of a vacincy on the Fe-site and a neighboring $\mathrm{Fe}$ antisite atom on the Alsite is suggested as the defect type responsible for the internal friction peak observed in FeAl [17].

In addition. divacincies are expected to play an important role in the interaction of dislocations 
with vacancies in $\mathrm{B} 2-\mathrm{FeAl}[18]$. By using the calculated divacancy binding enthalpy [18] of $\mathrm{H}_{2 \mathrm{v}}{ }^{\mathrm{B}}=\overline{0} .5$ $\mathrm{eV}$ and assuming a divacancy binding entropy of $S_{2 \mathrm{~V}}{ }^{\mathrm{B}}=1 k_{\mathrm{B}}$, it is estimated from the positron lifetime data [15] that $H_{\mathrm{v}}{ }^{\mathrm{F}}=0.89 \mathrm{eV}$ and $S_{\mathrm{v}}{ }^{\mathrm{F}}=4.2 k_{\mathrm{B}}$, where $k_{\mathrm{B}}$ is the Boltzmann constant. These are slightly lower than those values mentioned in the prededing paragraph, which do not take divacancies into account [15]. Using the above values, equilibrium mono-vacancy concentration, $c_{\mathrm{v}}$, defined as $n_{\mathrm{v}} / N$, are given by,

$$
c_{\mathrm{V}}=\exp \left(\frac{S_{\mathrm{V}}^{\mathrm{F}}}{k_{\mathrm{B}}}\right) \exp \left(-\frac{H_{\mathrm{v}}^{\mathrm{F}}}{k_{\mathrm{B}} T}\right)
$$

where $n_{\mathrm{V}}$ is the number of mono-vacancies, $N$ the total number of lattice sites, and $T$ the absolute temperature [19]. Equilibrium divacancy concentration, $c_{2 v}\left(\equiv n_{2 v} / N, n_{2 v}\right.$; the number of divacancies $)$, can be estimated by the following equation [19],

$$
c_{2 \mathrm{~V}}=g \cdot c_{\mathrm{v}}{ }^{2} \cdot \exp \left(\frac{H_{2 \mathrm{~V}}^{\mathrm{B}}-T S_{2 \mathrm{~V}}^{\mathrm{B}}}{k_{\mathrm{B}} T}\right)
$$

where $g$ is a divacincy configuration factor. In disordered alloys, $g=z / 2$, where $z$ is the coordination number of nearest neighbors. In B2-FeAl, thermal divacancies are formed between next-nearest neighbor sites [18, 20, 21], thus $z=6$ is adopted. Consequently, using eqnis. (1) and (2), the equilibrium concentration values are determined as: $c_{\mathrm{v}} \approx 10^{-14}$ for mono-vacancy and $c_{2 \mathrm{v}} \approx 10^{\prime \prime}$ for divaciancy at room temperature, and $c_{\mathrm{v}} \approx 0.01$ and $c_{2 \mathrm{v}} \approx 0.016$ at $1173 \mathrm{~K}$ arc estimated. These show that the equilibrium concentration of divaciancy is higher than that of mono-vacancy at high temperatures $(\geq 1073 \mathrm{~K})$.

In B2 structure, the number of lattice sites in the unit volume, $N_{0}$, is $2 / t^{3}\left(=6 \sqrt{3} / b^{3}\right)$, thus the number of mono- or divaciancies in the unit volume is $2 c_{\mathrm{v}_{\text {or } 2 \mathrm{v}}} / a^{3}\left(=6 \sqrt{3} c_{\mathrm{v}_{\mathrm{or}}} \mathrm{v}_{\mathrm{v}} / b^{3}\right)$, where $a$ is the lattice constant. $b$ the length of the Burgers vector. Considering the (110)[T11] slip. since the interplanar spacing of the $(110)$ plane is $a / \sqrt{2}$. the area of the $(110)$ plane in the unit volume is $\sqrt{2} / a$. The total number of mono- and divacincies is $c=c_{v}+c_{z v}=2 c / t^{3}$ in the unit volume. Thus, neglecting the configuration and orientation of divacancies, the vacancy concentration on the (110) plane is $\sqrt{2} c / c \dot{r}=$ 
$3 \sqrt{2} c / b^{2}$ ), and the mean distance between vacancies (or divacancies) on the (110) plane, $\bar{l}_{0}$, is

$$
\bar{l}_{0}=a / \sqrt{c \sqrt{2}}(=b / \sqrt{3 c \sqrt{2}})
$$

As an upper bound, when thermal vacancies at $1173 \mathrm{~K}$ are all frozen-in at room temperature, the activation volume of about $9 b^{3}$ for dislocation motion is estimated using eqn. (3). This value is comparable to the activation volume of dislocation motion controlled by the Peierls potential at low temperature in bcc metals.

The critical shear stress required for a dislocation to break away from two obstacles was represented by Fleischer and Hibbard [22] and Friedel [23] as follows;

$$
\tau=\frac{\mu b}{l_{0}}\left(\sin \frac{\theta_{c}}{2}\right)^{\frac{3}{2}}
$$

where $\mu$ is the shear modulus, and $\theta_{c}$ the critical angle for break-away from pinning points. Using eqn. (3), eqn. (4) is written as

$$
\tau \equiv 2 \mu\left(\sin \frac{\theta_{c}}{2}\right)^{\frac{3}{2}} c^{\frac{1}{2}}
$$

If the break-awaly stress given by eqn. (5) is high enough, the stress estimated by eqn. (5) gives the CRSS for B2-FeAl. Eqn. (5) shows that the CRSS is proportional to the square-root of supersaturated valcancy (or divalcancy) concentration. This relationship is consistent with that of hardness reponed by Pike et al. $[4,5]$ and the valcancy hardening model at elevated temperatures reported by George and Bakker $[24]$.

The experimental results on the CRSSs or yield stresses shown in Figs. 3 and 5 are discussed with the aid of Figure $11(\mu=64.8$ GPa [25, 26]), which shows the break-awaly stress from the equilibrium concentration of mono- and divacancies as a function of temperature. If one assumes the critical angle for mono-vacancies, to be $\theta_{i}^{\prime \prime}=5^{\prime \prime}$, and the pinning force of divacancies is twice that of mono-vacancies, i.c., $F_{: V}=2 F_{v}$, the critical angle for divacancies is estimated to be $\theta_{i}^{2 v}=10^{\prime \prime}$. Taking a hypothetical case of excess divacancies at room temperature. quenched-in from $1073 \mathrm{~K}$ by an infinitely 
fast' cooling rate, to represent the fast-cooled Specimen B from $1173 \mathrm{~K}$, the CRSS due to divacancies is estimated to be about $230 \mathrm{MPa}$. This value is in fair agreement with the experimental value interpolated at Fe-39Al of B2 phase in Fig. 5. In the meantime, the CRSS due to mono-vacancies at $1073 \mathrm{~K}$ is 78 $\mathrm{MPa}$. Although the concentration of mono-vacancies $\left(c_{\mathrm{v}} \approx 4.4 \times 10^{-3}\right)$ is almost the same as that of divacancies $\left(c_{2 \mathrm{v}} \approx 4.8 \times 10^{-3}\right)$ at the temperature, breaking away from mono-vacancies is not the rate controlling process in this case. The increase in the CRSS of Specimen B with increasing Al concentration (Fig. 5) is consistent with the decreasing trend of vacancy formation enthalpy found with increasing $\mathrm{Al}$ content [15].

\section{2. Work-Hardening Rate}

The negative strain-rate sensitivity of work-hardening observed in all three cases (A. B and C) of Fe-4l Al and Fe-44Al (Figs. 7 and 8) indicates that the dominant mechanism of work-hardening is due to the interaction of dislocations of the primary (101)[111] slip system with those of the other slip systems. Additionally. serrated flow observed during work-hardening of the fast-cooled specimens suggest that the interaction of dislocations with vacancies and its clusters also contributes significantly to the work-hardening rate at room temperature.

While the elastic interaction between a ( $\overline{1} 01)[111]$ slip dislocation and a vacancy is attractive loward the compressive zone of the dislocation's pressure field. the dislocation interaction with a divaleancy is expected to be anisotropic and relatively more complex because of the preferential adignment of two vacincies at the Fe-site along the [100] direction [27]. Once these vacincies and divacancies in the matrix lattice make direct contacts with a dislocation. these will create jogs on the dislocation and may leave behind dipoles and loops. Therefore. as plastic deformation proceeds, the total number of 'vacint' sites is decreased and the dislocation density is increased. The decrease in work-hardening rate observed between $\mathrm{Fe}-4 \mathrm{Al}$ and $\mathrm{Fe}-44 \mathrm{Al}$ (Fig. 6) suggests that there may be an optimum supersaturation of valciant sites that give rise to the maximum work-hardening. 


\section{3. Dislocation Microstructure}

According to the earlier analysis of dislocation line tension in elastically anisotropic FeAl [28], the dislocation line of [111] Burgers vector lying on the (101) plane is unstable in the angular range of $47.5^{\circ} \pm 9.5^{\circ}$ from the [111] direction. Almost all dislocations in as-homogenized Specimen A (Fig. 9) are out of the unstable range, meaning that the dislocations are arranged along elastically stable orientations. In contrast, however, dislocations in fast-cooled Specimen B (Fig. 10) are preferentially aligned along a direction which makes about $56^{\circ}$ from the [111] axis. This is just about $1^{\circ}$ within the unstable angular range for a glide loop.

As a large number of vacancies and divacancies are absorbed into a slip dislocation and migrate along the dislocation core by a pipe-diffusion mechanism, a distribution of jogs accumulated along the dislocation will take up a configuration such that the total energy (the elastic line and interaction energies and the core energy) is decreased. In other words, while a perfect glide dislocation of the (101)[111] slip system is unstable at the $56^{\circ}$ orientation, the climb component of this dislocation makes the postmortem TEM result of Fig. 10 a metastable inhomogencous microstructure, which can be related to the serrated-flow behavior observed in fast-cooled Specimen B. When such a dislocation breaks alway from jogs and superjogs under an applied stress, dipoles and loops are created behind the moving dislocation. which will in turn contribute to the work-hardening by dislocation-loop interaction.

\section{Cunclusions}

In this work, the effect of excess vacancies on the room temperature tensile properties of $\mathrm{Fe}-33$. 41 and $44 \mathrm{~mol} . \% \mathrm{Al}$ was investigated using single crystals.

1. Significant excess vacancy strengthening was detected over the aluminum composition examined. even in Fe-33mol. CrAl. Due to the excess vacancy strengthening. CRSS is increased drastically: and 
elongation is decreased.

2. Dislocation motion obstructed by excess vacancies is interpreted by the break-away process. In fast-cooled specimen, in which the supersaturation of divacancies is comparable to that of monovacancies, dislocation-divacancies interaction plays an important part of the strengthening mechanism.

3. The iron aluminides strengthened by excess vacancies exhibit serrated flow during work hardening. In $\mathrm{B} 2 \mathrm{FeAl}$, work hardening rate is lowered by excess vacancies.

4. Dislocations microstructure in $\mathrm{Fe}-44 \mathrm{~mol}$. \% Al were arranged inhomogeneously in the form of bundle structures. Mixed character is predominant in this microstructure, which is in the unstable range of the dislocation line orientation estimated by the anisotropic line-tension calculation.

\section{Acknowledgments}

The authors thank Dr. J. H. Schneibel and Dr. E. P. George for reviewing this paper. This rescarch was sponsored by the program of Japan Society for the Promotion of Science Postdoctoral Fellowships for Rescarch Abroad, and in part by the Division of Materials Sciences, U.S. Department of Energy, under Contract No. DE-AC05-96OR22464 with Lockheed Martin Energy Research Corp.

\section{References}

1. P. Nagpal and I. Baker. Metall. Trans. A, 21 (1990), 2281.

2. J. Ricu and C. Guux, Mém. Sci. Rev. Metall., 65 (1969), 869.

3. D. Weber, M. Meurtin. D. Paris, A. Fourdeux and P. Lesbats, J. Phys. C7, 38 (1997), 332

4. Y. A. Chang. L. M. Pike. C. T. Liu, A. R. Bilbrey and D. S. Stone, Intermetedlics, I (1993). 107.

5. L. M. Pike, Y. A. Chang and C. T. Liu, Acta Mater., 45 (1997), 3709.

6. H. Kimura and R. Maddin. in Quenching Hardening in Metals, North-Holland Publishing 
Company, Amsterdam / London, (1971).

7. J. P. Rivière, H. Zonon and J. Grilhé, Phys. Stat. Sol. (a), 16 (1973), 545.

8. M. A. Crimp and K. Vedula, Phil. Mag. A, 63 (1991)559.

9. D. G. Morris, J. C. Loye and M. Leboeuf, Phil. Mag. A, 69 (1994), 961.

10. K. Yoshimi, S. Hanada and M. H. Yoo, Acta Metall. Mater., 43 (1995), 4141.

11. K. Yoshimi, S. Hanada and M. H. Yoo, Intermetallics, 4 (1996), 159.

12. K. Yoshimi, S. Hanada and M. H. Yoo, Intermetallics, 4 (1996), S159.

13. K. Yoshimi and S. Hanada, JOM, vol. 49 (1997), no. 8, p. 46.

14. K. Yoshimi and S. Hanada, in Structure Intermetallics, ed. by R. Darolia, J. J. Lewandowski, C. T. Liu, P. L. Martin, D. B. Miracle and M. V. Nathal. TMS Publications, Warrendale, PA, (1993), p. 475.

15. R. Würschum, C. Grupp and H. -E. Schaefer, Phys. Rev. Lett., 75 (1995), 97.

16. R. Carleton, E. P. George and R. H. Zee, Intermetallics, 3 (1995), 433.

17. H. -E. Schaefer, B. Damson, M. Weller, E. Arzt and E. P. George, Phys. Stct. Sol. (a), 160 (1997), 531 .

18. C. L. Fu, Y. -Y. Ye. M. H. Yoo and K. M. Ho, Phys. Rev. B, 48 (1993), 6712.

19. A. C. Damask and G. J. Dienes, in Point Defects in Metdls, Gordon and Breach. Science Publishers, New York. (1963).

20. D. Paris, P. Lesbats and J. Levy, Scripta Metall., 9 (1975), 1373.

21. R. Krachler. H. Ipser. B. Sepiol and G. Vogel, Intermetallics, 3 (1995), 83.

22. R. L. Fleischer and W. R. Hibbard, Jr., in The Relation benveen the Structure and Mechorical Properties of Metals, H. M. S. O., London, (1963), p.261.

23. J. Friedel, in Electron Microscopy cond Strength of Crystals, ed. by G. Thomas and J. Washburn. Interscience. New York. (1963), p. 605.

24. E. P. George and I. Baker. Phil. Mag. A, in press.

25. H. J. Leamy. E. D. Gibson and F. X. Kayser, Acta Metall., 15 (1967), 1827. 
26. M. J. Marcinkowski and G. Lakso, J. Appl. Phys., 38 (1967), 2124.

27. C. L. Fu and X. -D. Wang, Mater. Sci. Eng., to be published.

28. K. Yoshimi, N. Matsumoto, S. Hanada and M. H. Yoo, in Processing, Properties, and Applications of Iron Aluminides, ed. by J. H. Schneibel and M. A. Crimp. TMS Publication, Warrendale, PA, 1994, p. 205. 
(a)

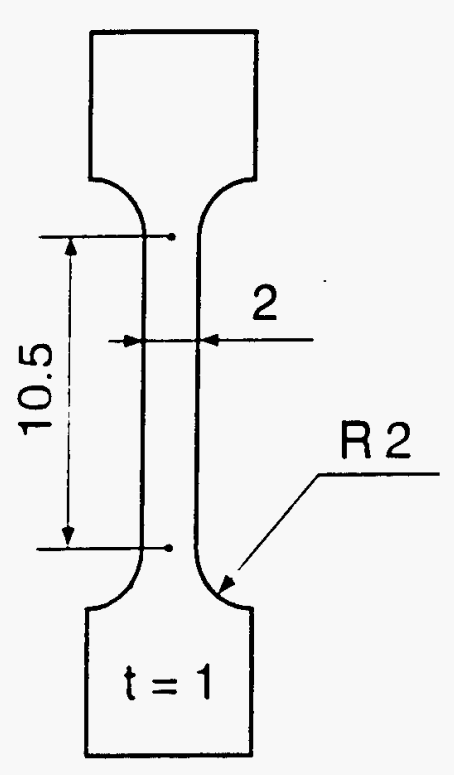

(b)

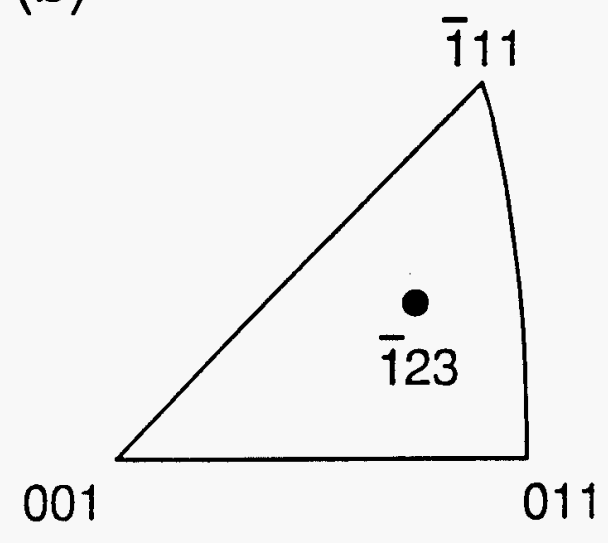

Fig. 1 (a) Shape and size of tensile specimen. The unit is ' $\mathrm{mm}$ '. (b) Tensile axis close to [123] shown in the standard [001]-[011]-[i11]] unit triangle.

Yoshimi et al. 


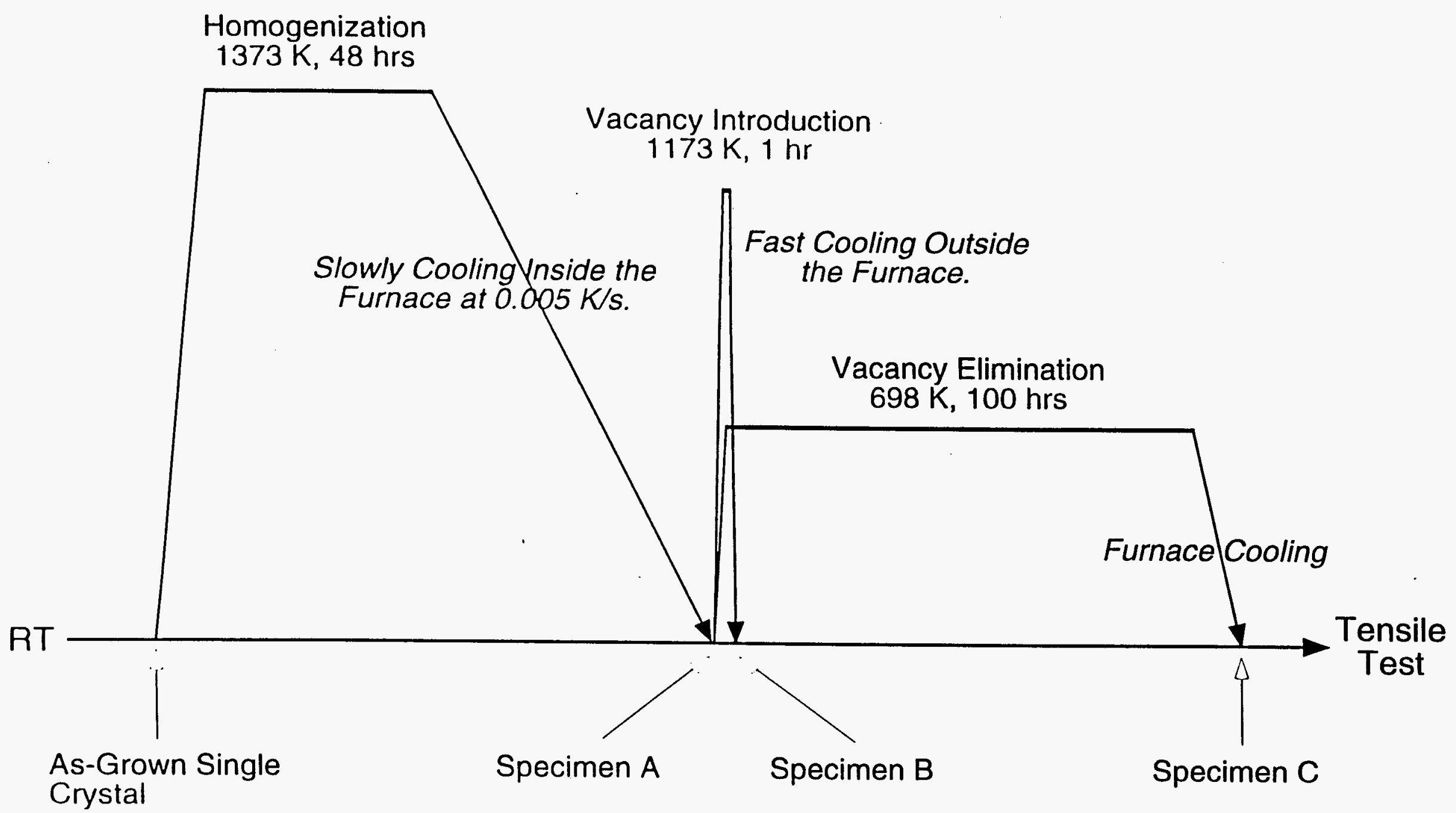

Yoshimi et al. Fig. 2. Schematic diagram of thermal histories of tensile specimens. 


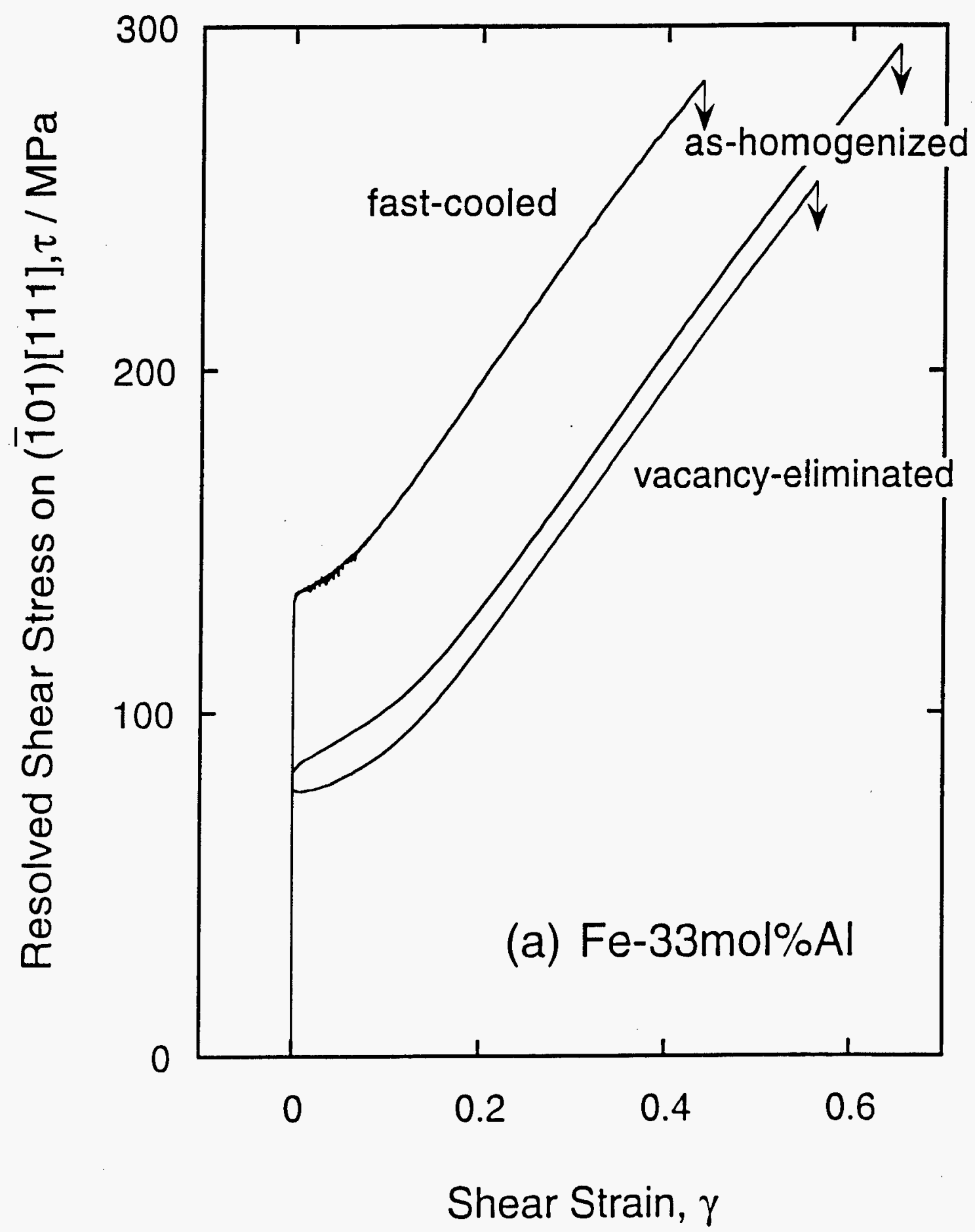

Fig. 3. Resolved shear stress-strain curves of Fe-Al subjected to three different heat treatments. (a) Fe-33mol.\%Al. (b) Fe-4l mol.\% Al. (c) $\mathrm{Fe}-4+$ mol.. $\mathrm{Al}$.

Yoshimi et al. 


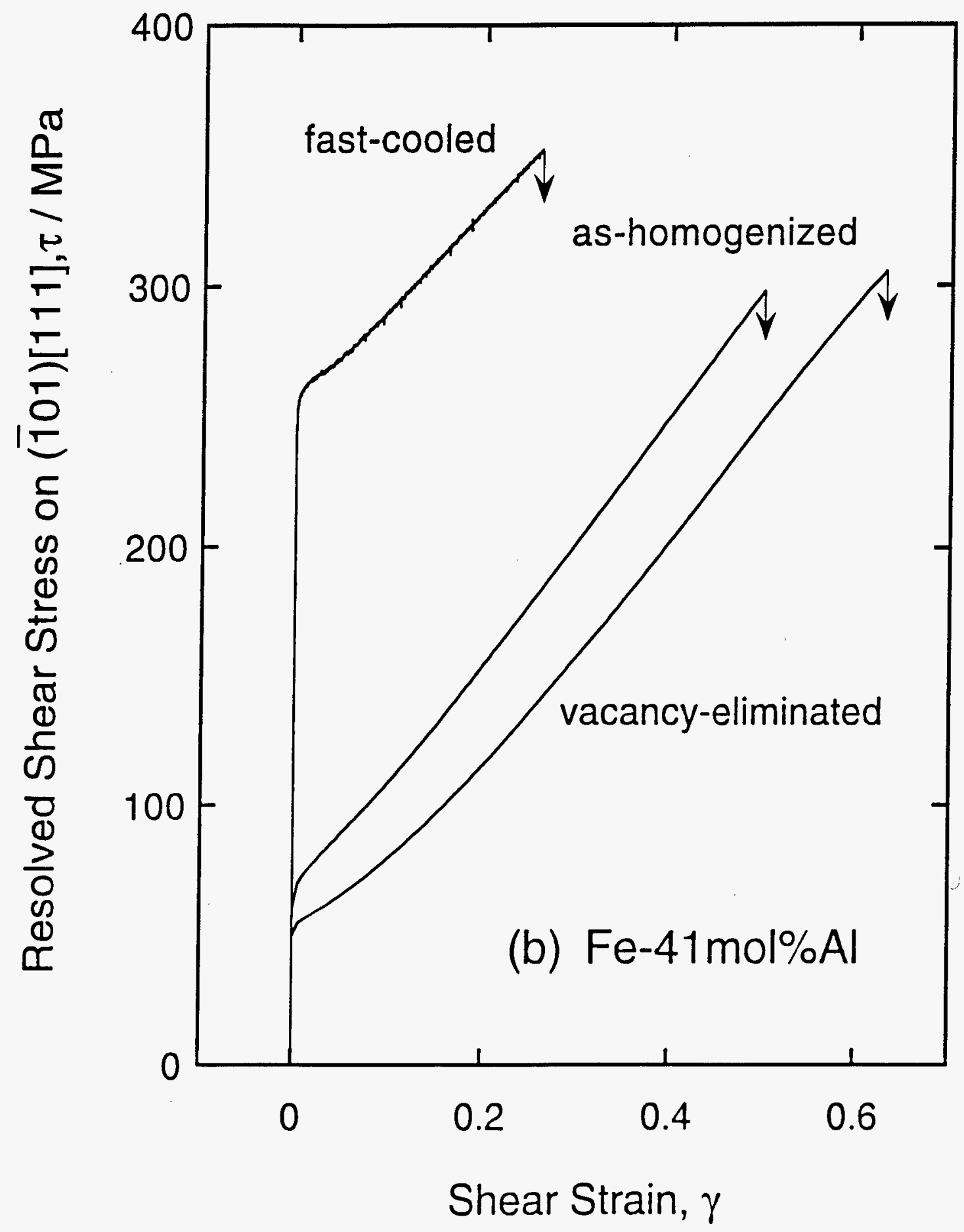

Fig. 3. (continued)

Yoshimi et al. 


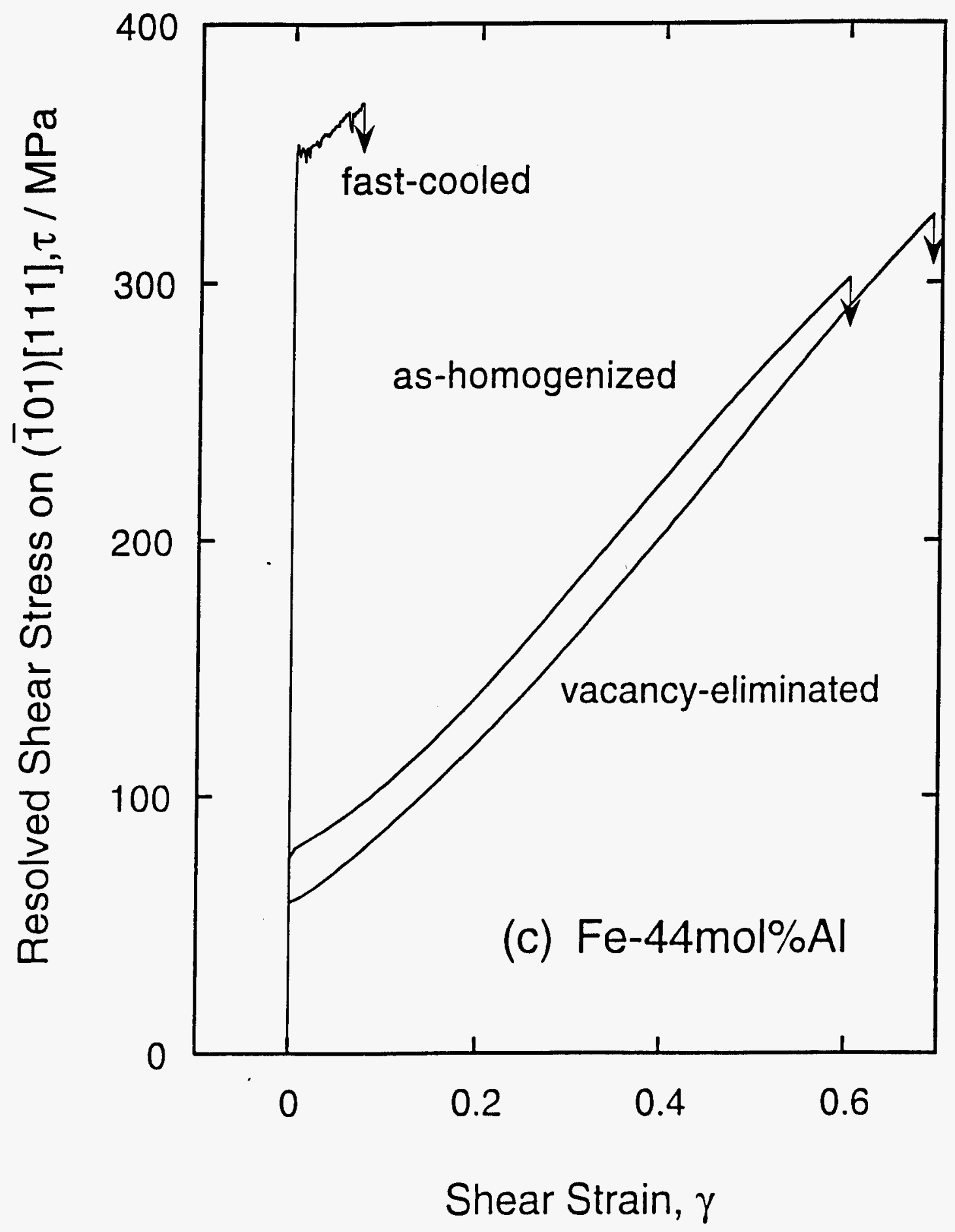

Fig. 3. (continued)

Yoshimi et al. 


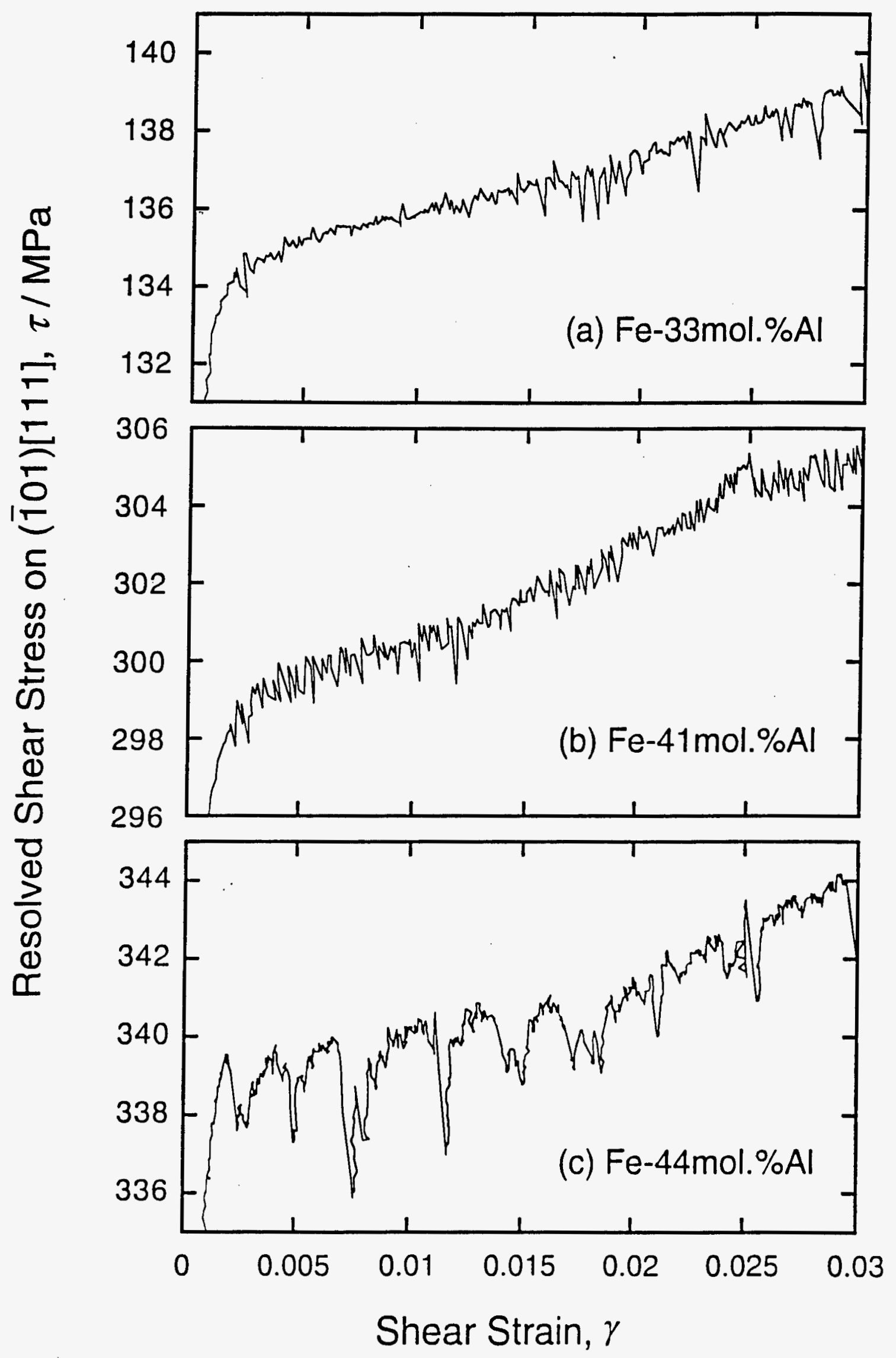

Fig. 4. Serrated flow of fast-cooled tensile specimens. (a) Fe-33mol. \% Al. (b) Fe-tlmol.? Al. (c) Fe-t4mol.Al. 


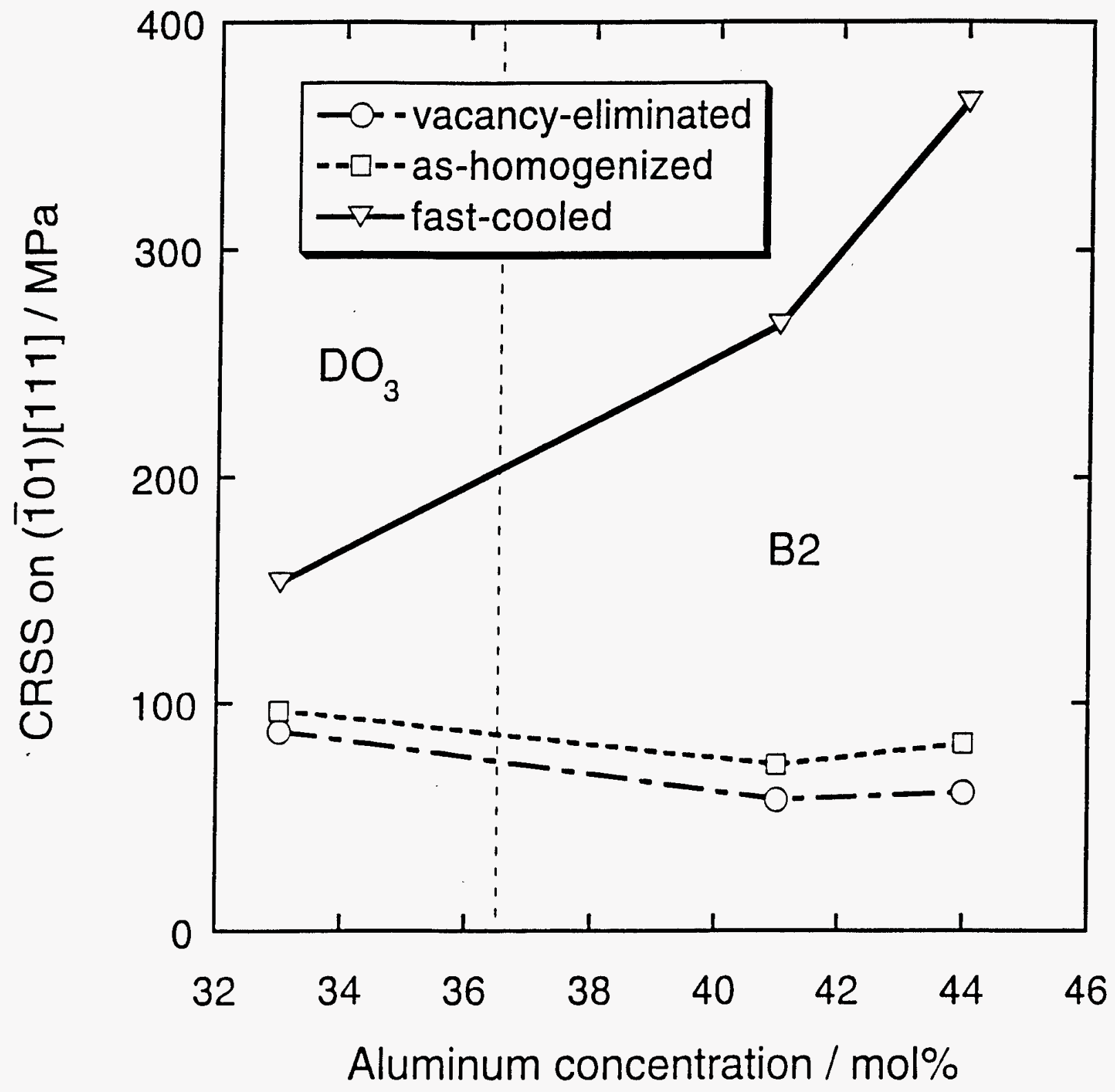

Fig. 5. CRSS against aluminum concentration.

Yoshimi et al. 


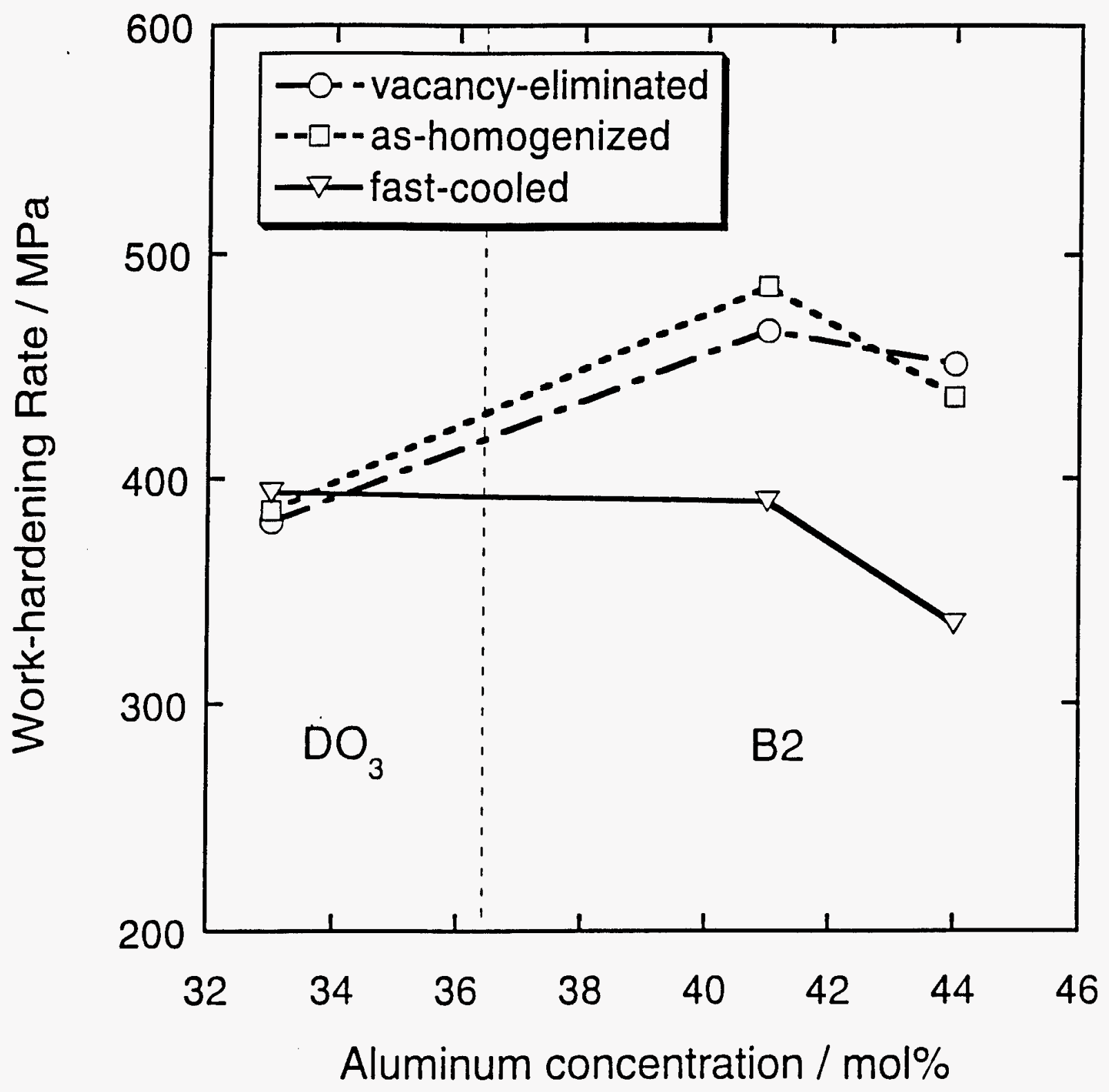

Fig. 6. Work-hardening rate against aluminum concentration. 
Resolved Shear Stress /MPa

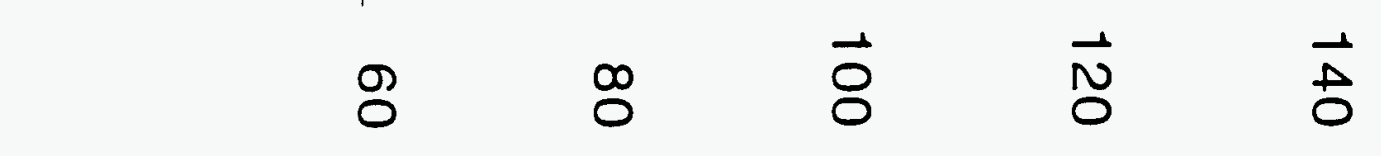

S

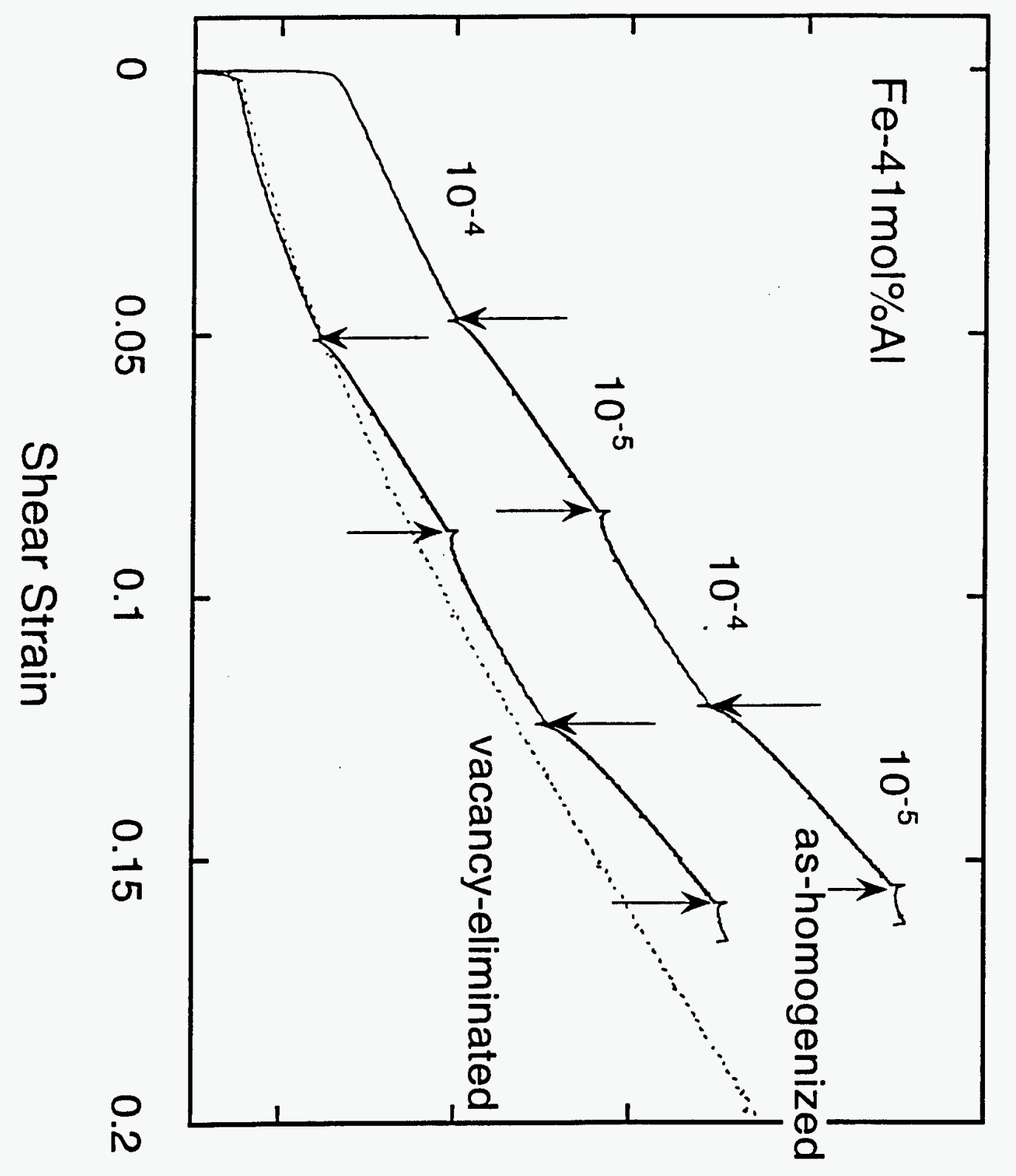

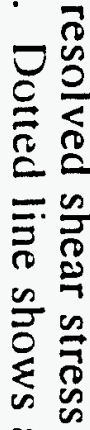

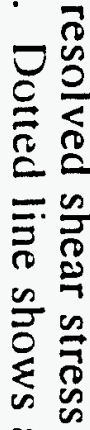

$\bar{\nabla}$

$\frac{\pi}{2}$

is is

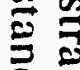

을

을

is

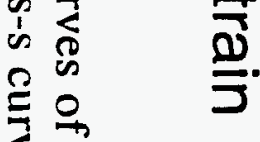

i I

$\sum \stackrel{P}{1}$

$\equiv$

훙

$\infty$

긴

当

$\overrightarrow{0}$

के

$\stackrel{2}{3}$

赵

逭. 
Resolved Shear Stress / MPa
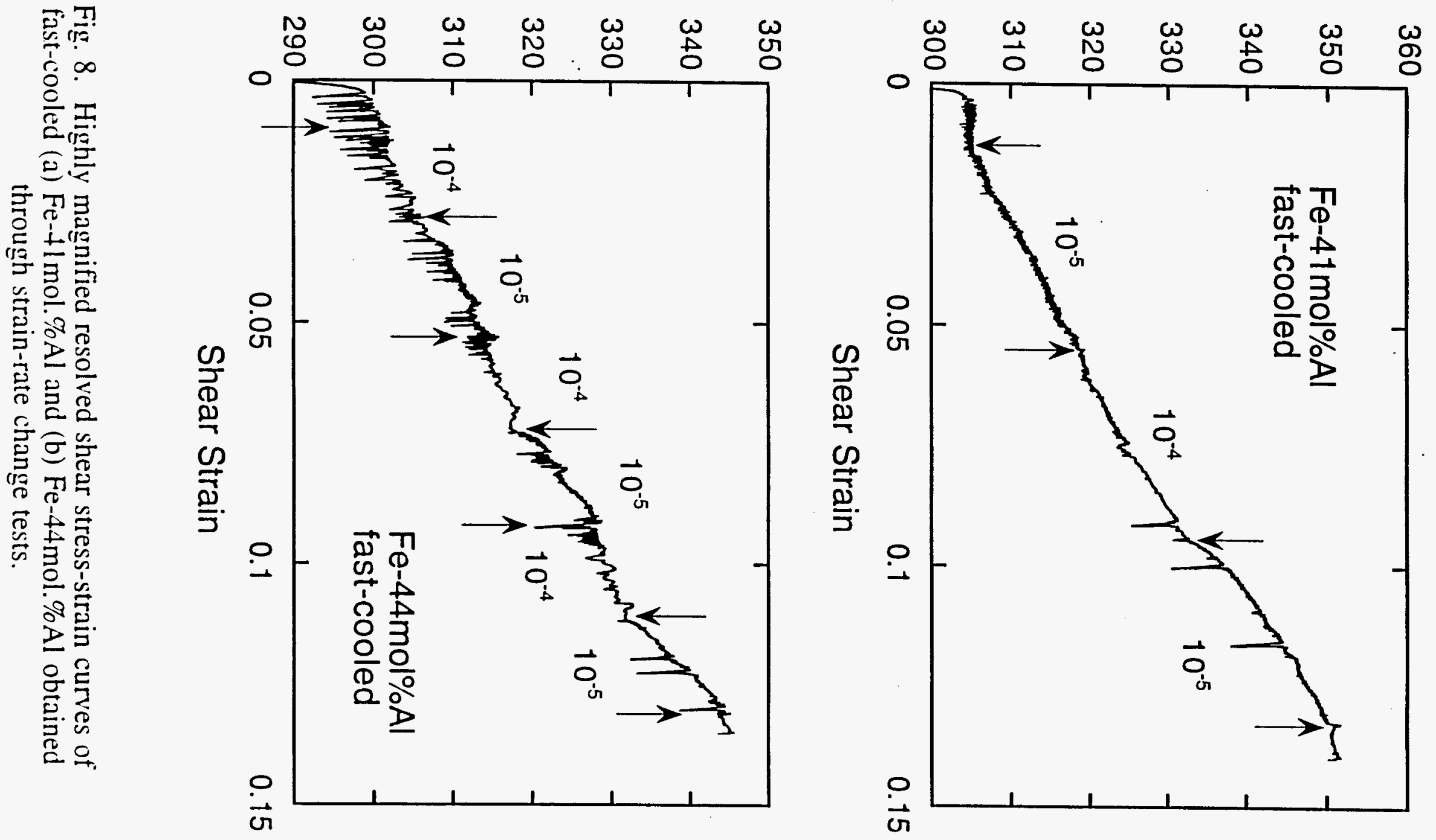


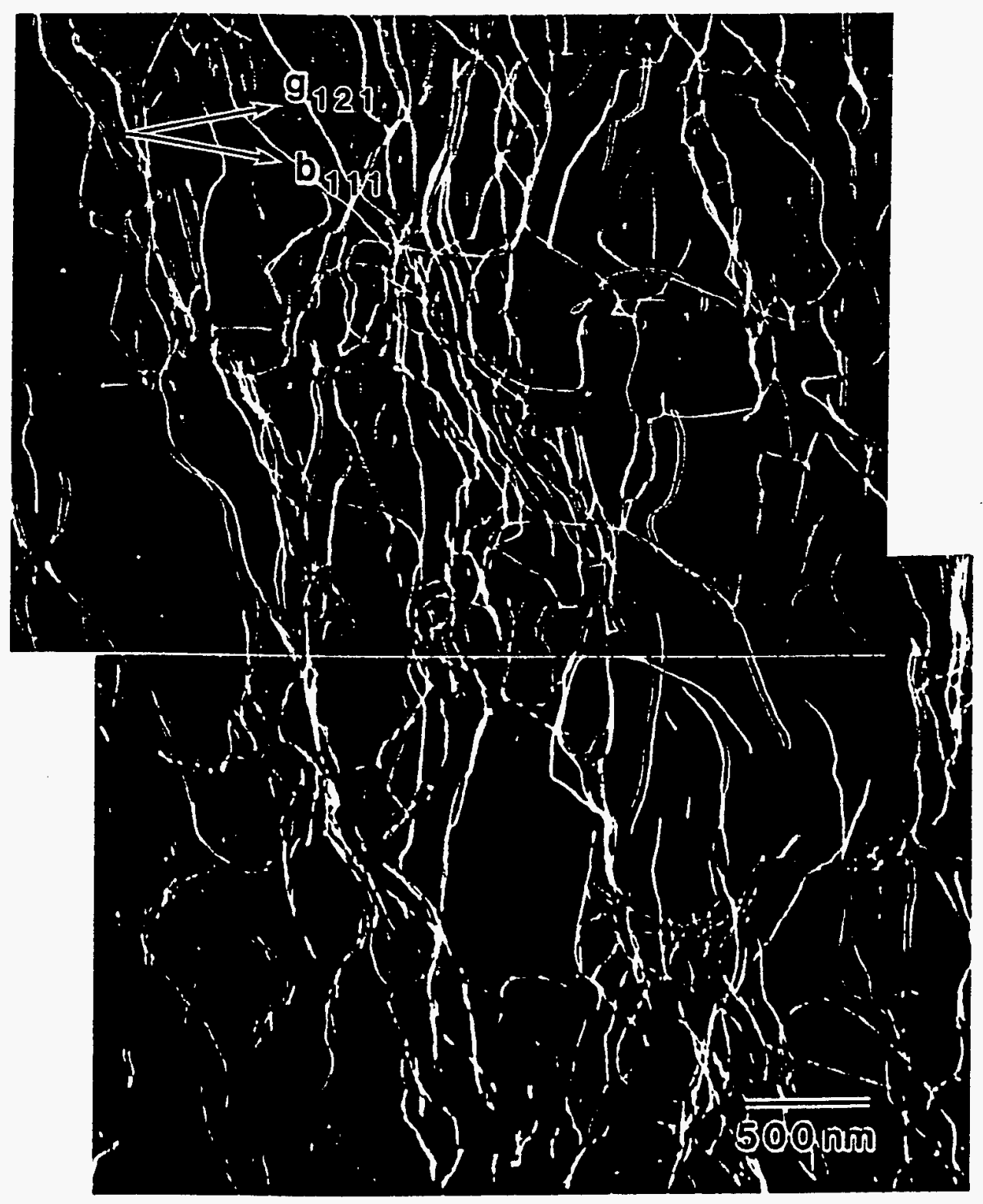

Fig. 9. Deformation microstructure of as-homogenized Fe-44mol.\%Al single crystal (Specimen A) strained up to about $4 \%$. It was taken in $\mathbf{g}-3 \mathrm{~g}$ weak-beam condition with $g=121$. The incident beam direction and the normal of the thin foil plane is almost parallel to the [ī01] direction.

Yoshimi et al. 


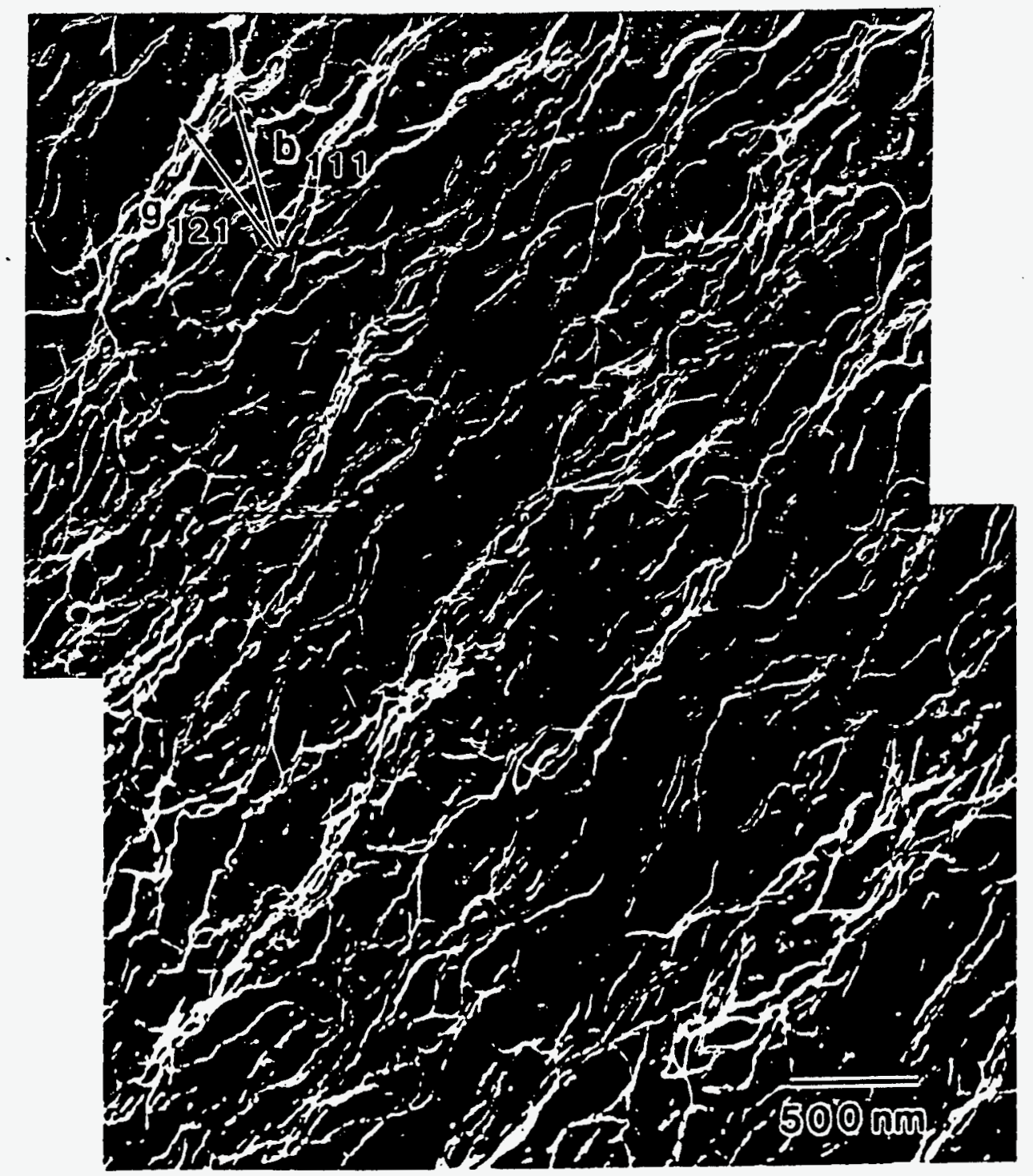

Fig. 10. Deformation microstructure of fast-cooled Fe-44mol.\%Al single crystal (Specimen B) strained up to about $4 \%$. It was taken in $\mathbf{g}-3 \mathbf{g}$ weak-beam condition with $g=121$. The incident beam direction and the normal of the thin foil plane is almost parallel to the $[\overline{1} 01]$ direction.

Yoshimi et al. 


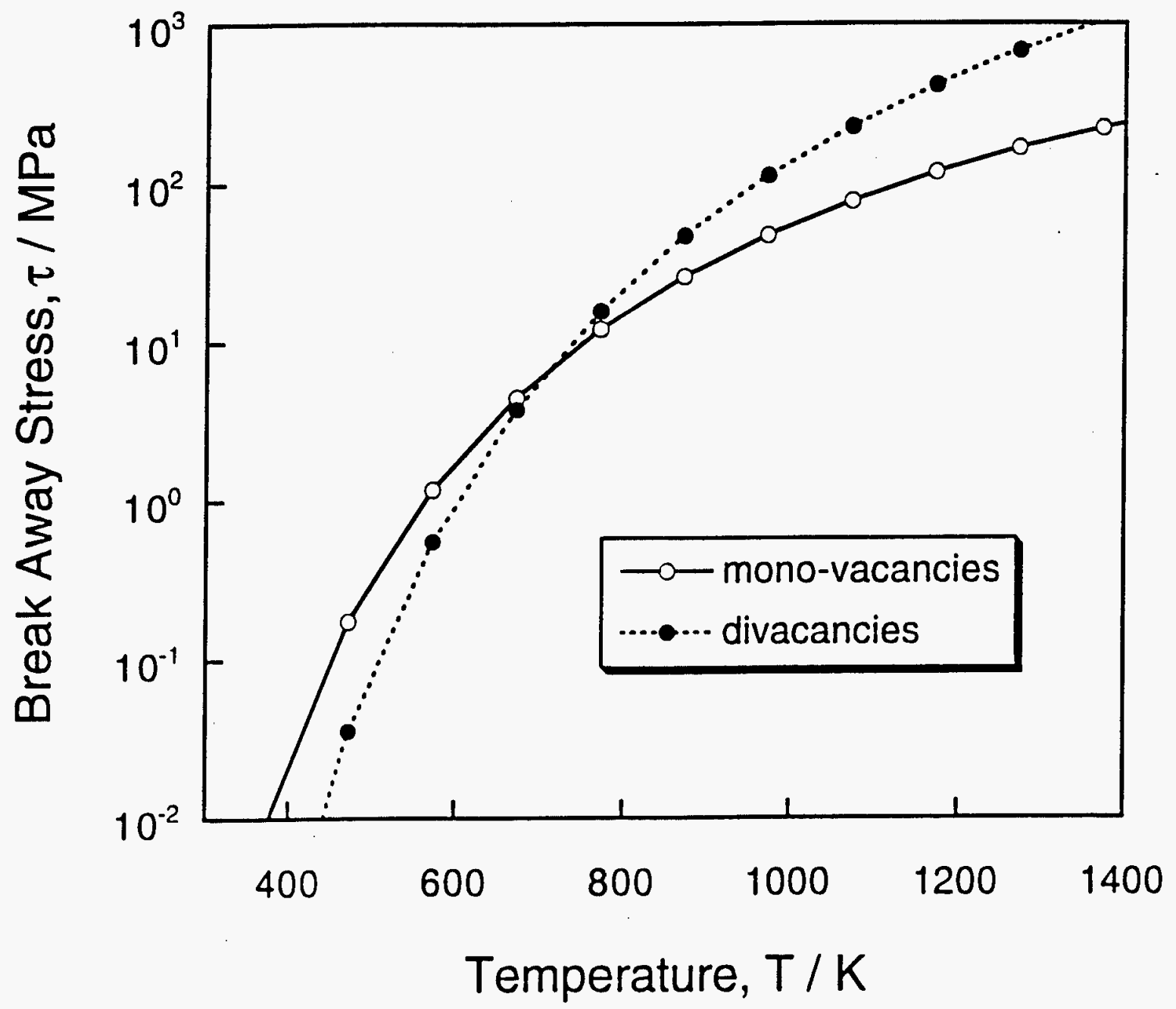

Fig. 11. Break away stress from the equilibrium concentration of monoand divacancies as a function of temperature. 

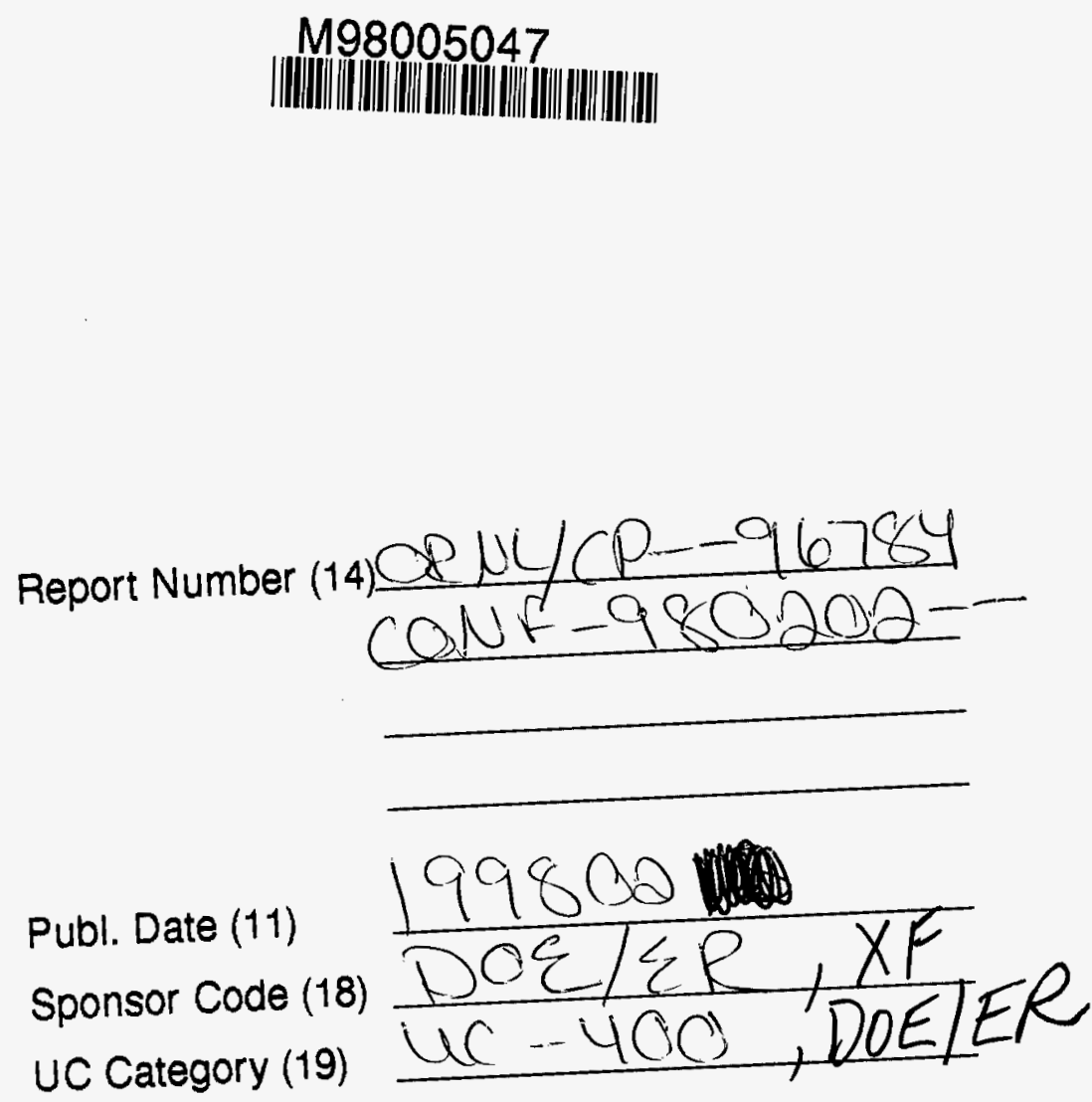

\section{5}

